\title{
Dessecação pré-colheita de soja e Brachiaria brizantha consorciadas com doses reduzidas de graminicida
}

\author{
Andréia Cristina da Silva ${ }^{(1)}$, Francisco Cláudio Freitas ${ }^{(2)}$, Lino Roberto Ferreira(2) e Rogério Soares Freitas ${ }^{(1)}$
}

(1)Agência Paulista de Tecnologia dos Agronegócios, Pólo Regional Alta Sorocabana, Caixa Postal 298, CEP 19001-970 Presidente Prudente, SP. E-mail: andreiacs@aptaregional.sp.gov.br (2)Universidade Federal de Viçosa, Dep. de Fitotecnia, CEP 36571-000 Viçosa, MG. E-mail: Iroberto@.ufv.br

\begin{abstract}
Resumo - O objetivo deste trabalho foi avaliar os efeitos da dessecação pré-colheita de soja consorciada com Brachiaria brizantha cv. Marandu, com doses reduzidas de graminicida, na viabilização de colheita mecânica de soja e na capacidade de rebrota e formação de palha de $B$. brizantha. Foi utilizado esquema fatorial 5x3, com cinco doses do graminicida fluazifop-p-butil - 0, 15, 30, 45 e $60 \mathrm{~g} \mathrm{ha}^{-1}$ - e três manejos de dessecação do consórcio - sem dessecação e com dessecação nos estádios R7 ou R8 da soja -, em delineamento de blocos casualizados, com quatro repetições. Foram avaliadas duas testemunhas, soja e B. brizantha em monocultivo, capinadas manualmente. A braquiária foi altamente suscetível à ação do graminicida. O consórcio entre soja e B. brizantha, submetido a $15 \mathrm{~g} \mathrm{ha}^{-1}$ de graminicida e dessecado no estádio R7 da soja, permitiu a colheita mecânica da soja e a produção de grãos semelhante à alcançada no monocultivo, proporcionando acúmulo de matéria seca de $B$. brizantha de 4,6 t ha ${ }^{-1}$, 60 dias depois da colheita da soja. A B. brizantha consorciada com soja, sem aplicação de graminicida, acumulou $6 \mathrm{t} \mathrm{ha}^{-1}$ de matéria seca na colheita da soja e 9,3 t ha ${ }^{-1} 60$ dias depois da colheita da soja, e o acúmulo de matéria seca de $B$. brizantha em monocultivo, nessas duas épocas, foi de 13,3 e 21,6 t ha-1, respectivamente.
\end{abstract}

Termos para indexação: Glycine max, braquiária, plantio direto, cobertura morta, manejo.

\section{Pre-harvest desiccation of soybean intercropped with Brachiaria brizantha under reduced doses of graminicide}

\begin{abstract}
The objective of this work was to evaluate the effects of pre-harvest desiccation of soybean and Brachiaria brizantha cv. Marandu, treated with reduced doses of graminicide under intercropping system on soybean mechanical harvest as well as forage regrowth and straw yield. A $5 \times 3$ factorial scheme was used, consisting of five rates of fluazifop-p-butyl (0, 15, 30, 45 and $60 \mathrm{~g} \mathrm{ha}^{-1}$ ) and three intercropping desiccation managements, without desiccation or desiccated at R7 or R8 soybean stage, in a randomized complete block, with four replications. Two control treatments were included; soybean and B. brizantha under monocrop kept clean by hand hoeing. $B$. brizantha was highly susceptible to herbicide. Soybean and B. brizantha intercropped at $15 \mathrm{~g} \mathrm{ha}^{-1}$ of graminicide and desiccated at R7 soybean stage allowed soybean mechanical harvest and grain yield similar to those achieved under monocrop, providing dry mass accumulation of $B$. brizantha of $4.6 \mathrm{tha}^{-1}$, 60 days after soybean harvest. B. brizantha intercropped with soybean, without graminicide application, accumulated $6 \mathrm{t} \mathrm{ha}^{-1}$ of dry mass at soybean harvest and $9.3 \mathrm{t} \mathrm{ha}^{-1}, 60$ days after, with mass accumulation of B. brizantha under monocrop being 13.3 and $21.6 \mathrm{t} \mathrm{ha}^{-1}$, respectively.
\end{abstract}

Index terms: Glycine max, no-till, mulching, management.

\section{Introdução}

O sistema de plantio direto tem-se mostrado muito mais que um método de conservação do solo e vem contribuindo para a sustentabilidade da agricultura, mantendo altas produções, sem danificar o solo e o meio ambiente (Amaral, 2001). Entre as culturas anuais, a soja destacase no plantio direto, principalmente na rotação com pastagens e outras forrageiras, revolucionando a produção agropecuária (Saturnino, 2001).
Embora largamente adotado, o sistema de plantio direto dependerá, para sua evolução, de fontes eficientes de cobertura morta, capazes de proteger plenamente a superfície do solo e ter longevidade adequada. A palha formada pelas espécies do gênero Brachiaria atende a esses dois quesitos, produzindo mais de 15 t ha-1 de matéria seca quando corretamente manejada e persistindo por mais de seis meses na superfície do solo (Cobucci, 2001). A cultura da soja apresenta baixa relação $\mathrm{C} / \mathrm{N}$ e, por isso, é fundamen- 
tal a introdução de espécies em rotação ou consorciação que proporcionem cobertura do solo para a viabilização do plantio direto.

Tem sido proposta recentemente a consorciação entre soja e $B$. brizantha, utilizando-se doses reduzidas de graminicida, a fim de minimizar a competição da forrageira com a leguminosa. Entretanto, um dos entraves à adoção dessa prática é a colheita da soja com a presença da forrageira, uma vez que a altura da barra de corte da colheitadeira é baixa, o que inviabiliza a colheita mecânica (Silva et al., 2004). Esse sistema permite o emprego da forrageira, depois da colheita da soja, como pasto para o gado ou a sua dessecação por meio de herbicidas para formação de cobertura morta para o plantio direto.

A utilização de herbicidas dessecantes na fase de pré-colheita da soja tem sido amplamente estudada (Andreoli \& Beltoft, 1979; Batista Filho \& Barros, 1980; Durigan \& Carvalho, 1980; Almeida et al., 1991). Os agricultores procedem à dessecação em lavouras infestadas, com a finalidade de controlar plantas daninhas e provocar a desfolha da cultura. O procedimento facilita o trabalho das colheitadeiras e permite a antecipação da colheita, com redução dos prejuízos decorrentes de fungos e pragas que incidam sobre a cultura no final do ciclo (Almeida et al., 1991).

Herbicidas do grupo dos bipiridilos (paraquat e diquat) são muito utilizados como dessecantes em várias culturas, com eficiência comprovada na cultura da soja (Batista Filho \& Barros, 1980; Durigan \& Carvalho, 1980). A B. brizantha é uma espécie perene e, por isso, a utilização do paraquat, herbicida com ação de contato, permite a rebrota da forrageira, e é uma alternativa para viabilizar a colheita da soja no sistema consorciado e, posteriormente, a recuperação da pastagem.

O objetivo deste trabalho foi avaliar os efeitos da dessecação com paraquat na pré-colheita da soja consorciada com B. brizantha, com doses reduzidas de graminicida, na viabilização de colheita mecânica de soja, na capacidade de rebrota e na formação de palha de B. brizantha.

\section{Material e Métodos}

O experimento foi instalado em Viçosa, MG, no ano agrícola de 2003/2004, em solo classificado como Argissolo Vermelho-Amarelo câmbico, textura argilosa, cujas principais características químicas são: $\mathrm{pH}$ em água, 6,7; MO, 4,12 dag kg-1; V, 79\%; P e K, 243,7 e 260,0 $\mathrm{mg} \mathrm{dm}^{-3}$, respectivamente; e Ca, $\mathrm{Mg}, \mathrm{H}+\mathrm{Al}, 5,9$, 1,0 e $1,98 \mathrm{cmol}_{\mathrm{C}} \mathrm{dm}^{-3}$, respectivamente. A temperatura média, a umidade relativa do ar e a precipitação pluvial referentes ao período de condução do ensaio são apresentadas na Figura 1.

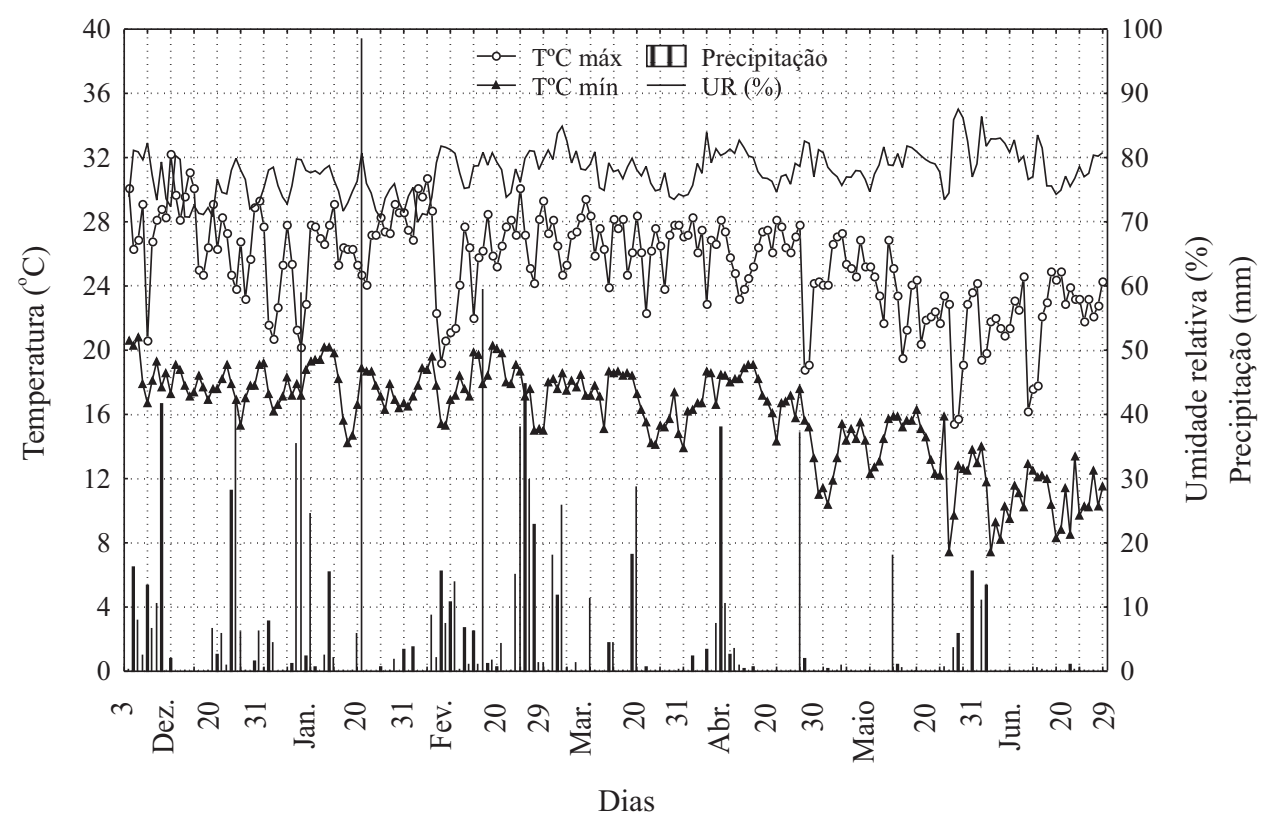

Figura 1. Temperatura máxima e mínima, umidade relativa e precipitação pluvial, referentes ao período de condução do ensaio. 
O experimento foi implantado em sistema de plantio direto, após a dessecação química $\left(1,8 \mathrm{~L} \mathrm{ha}^{-1}\right.$ de glifosato) da cobertura vegetal composta por plantas daninhas. As semeaduras da soja (Glycine max cv. UFV-16) e de B. brizantha cv. Marandu foram feitas simultaneamente em 3/12/2003, utilizando-se a semeadora para plantio direto Semeato. O espaçamento entre as linhas de soja foi de $0,60 \mathrm{~m}$, obtendo-se estande de 220 mil plantas por ha, sendo a $B$. brizantha semeada entre as linhas da soja $\left(7 \mathrm{~kg} \mathrm{ha}^{-1}\right.$ de sementes). A unidade experimental foi de $18 \mathrm{~m}^{2}$, sendo de $7,2 \mathrm{~m}^{2}$ a área útil para as avaliações. As sementes de soja foram submetidas à inoculação das estirpes SEMIA 587 e SEMIA 5019, de Bradyrhizobium japonicum. A adubação de plantio consistiu de $200 \mathrm{~kg} \mathrm{ha}^{-1}$ da formulação 8-28-16. Todos os tratos culturais e fitossanitários necessários foram realizados. No controle de plantas daninhas dicotiledôneas, utilizou-se o fomesafen $\left(0,2 \mathrm{~kg} \mathrm{ha}^{-1}\right)$ em área total, aplicado 17 dias depois da emergência da soja (DAE).

O experimento foi montado seguindo esquema fatorial $5 \times 3$, sendo cinco doses de fluazifop-p-butil ( 0 , $15,30,45$ e $60 \mathrm{~g} \mathrm{ha}^{-1}$ ) e três manejos de dessecação do consórcio - sem dessecação e dessecação com paraquat no estádio R7 ou R8 da soja -, no delineamento em blocos casualizados, com quatro repetições. Foram adotadas duas testemunhas, $B$. brizantha e soja em monocultivo, capinadas manualmente.

O graminicida foi aplicado 23 dias depois da emergência da soja, utilizando-se pulverizador costal pressurizado com $\mathrm{CO}_{2}$, equipado com barra de dois bicos TT110.02, espaçados de 1,0 m, à pressão constante de 2,5 $\mathrm{kgf} \mathrm{cm}^{-2}$, aplicando-se o equivalente a $100 \mathrm{~L} \mathrm{ha}^{-1}$ de calda.

Nos estádios R7 e R8 da soja (Fehr et al., 1971), as espécies consorciadas foram dessecadas com paraquat (400 $\mathrm{g} \mathrm{ha}^{-1}+0,55 \mathrm{~L}$ de espalhante adesivo Aterbane). O teor de água dos grãos da soja, por ocasião das aplicações, foi de 50\% no estádio R7 e de $20 \%$ no R8.

Na colheita da soja, foram atribuídas notas referentes ao grau de dificuldade de colheita mecânica de acordo com a presença de $B$. brizantha, utilizando-se escala de 1 (perfeitamente viável) a 5 (inviável).

A colheita da soja foi realizada manualmente, dez dias depois da segunda dessecação (134 DAE), coletandose todas as plantas da área útil. Determinaram-se o teor de umidade dos grãos, o estande final e a produtividade da cultura, depois da correção do teor de umidade dos grãos para 13\%. O peso de 100 sementes foi obtido de amostra retirada do total de sementes colhidas na área útil da unidade experimental. Foram determinados o número de vagens por planta e a altura das plantas e de inserção da primeira vagem, em dez plantas amostradas na área útil da unidade experimental.

Depois da colheita da soja, nos tratamentos em que não foi feita a dessecação, a parte aérea de B. brizantha foi amostrada em $0,5 \mathrm{~m}^{2}$ na área útil das parcelas. O material vegetal coletado foi secado em estufa de circulação forçada de ar a $70 \pm 1^{\circ} \mathrm{C}$, para determinação de matéria seca.

Dois meses depois da colheita da soja, foi feita amostragem de $B$. brizantha em todos os tratamentos, coletando-se plantas contidas em $0,5 \mathrm{~m}^{2}$, na área útil das parcelas.

Os dados foram submetidos à análise de variância. Para características significativas entre diferentes doses do graminicida, foram ajustadas curvas de regressão. Os manejos de dessecação foram comparados dentro de cada dose do graminicida, pelo teste de Tukey a 5\% de probabilidade. Na comparação das testemunhas em monocultivo com os tratamentos consorciados, foi utilizado o teste de Dunnett a 5\% de probabilidade.

\section{Resultados e Discussão}

Verificou-se efeito de doses do graminicida na produção de grãos e número de vagens da soja. O efeito de manejos não foi significativo, já que, na dessecação precoce (estádio R7 da soja), os grãos apresentavam máximo acúmulo de matéria seca. Segundo Ritchie et al. (1982), reduções no rendimento ocasionadas por estresse são menores quando as sementes já acumularam quantidades consideráveis de matéria seca; a partir do estádio R7, o rendimento não é mais afetado.

Houve redução de produtividade de grãos quando não foi aplicado o graminicida (dose zero), em virtude da maior interferência de $B$. brizantha. Todavia, observouse que $15 \mathrm{~g} \mathrm{ha}^{-1}$ do graminicida promoveram pronunciado aumento na produtividade de grãos, que se estabilizou nas demais doses. Somente a soja que recebeu a dose zero apresentou rendimento de grãos inferior à soja em monocultivo. B. brizantha cv. Marandu mostrou-se altamente suscetível ao graminicida, visto que a maior dose utilizada 
$\left(60 \mathrm{~g} \mathrm{ha}^{-1}\right)$ correspondeu a aproximadamente $67 \%$ do limite inferior recomendado para a cultura $\left(90 \mathrm{~g} \mathrm{ha}^{-1}\right)$ (Rodrigues \& Almeida, 1998) (Figura 2).

O componente de produtividade de grãos mais afetado foi o número de vagens, o qual seguiu o mesmo padrão de resposta da produtividade (Figura 2). Silva et al. (2004) verificaram tendência semelhante com B. brizantha cv. MG5. Entretanto, a cultivar Marandu utilizada neste ensaio mostrou-se menos competitiva com a soja em relação à cultivar MG5, o que pode ser atribuído à germinação mais tardia, ao crescimento menos vigoroso e ao porte mais prostrado, que favoreceram a soja.

Quanto ao peso de 100 sementes, estande final, altura das plantas e de inserção da primeira vagem, não foi verificado efeito dos tratamentos, sendo a média dessas características de 17,52 g, 216 mil plantas, $98,71 \mathrm{~cm}$ e $21,86 \mathrm{~cm}$, respectivamente. Houve efeito de manejos de dessecação no teor de umidade dos grãos de soja, determinada em seguida à colheita. Plantas não-dessecadas apresentaram grãos com maior
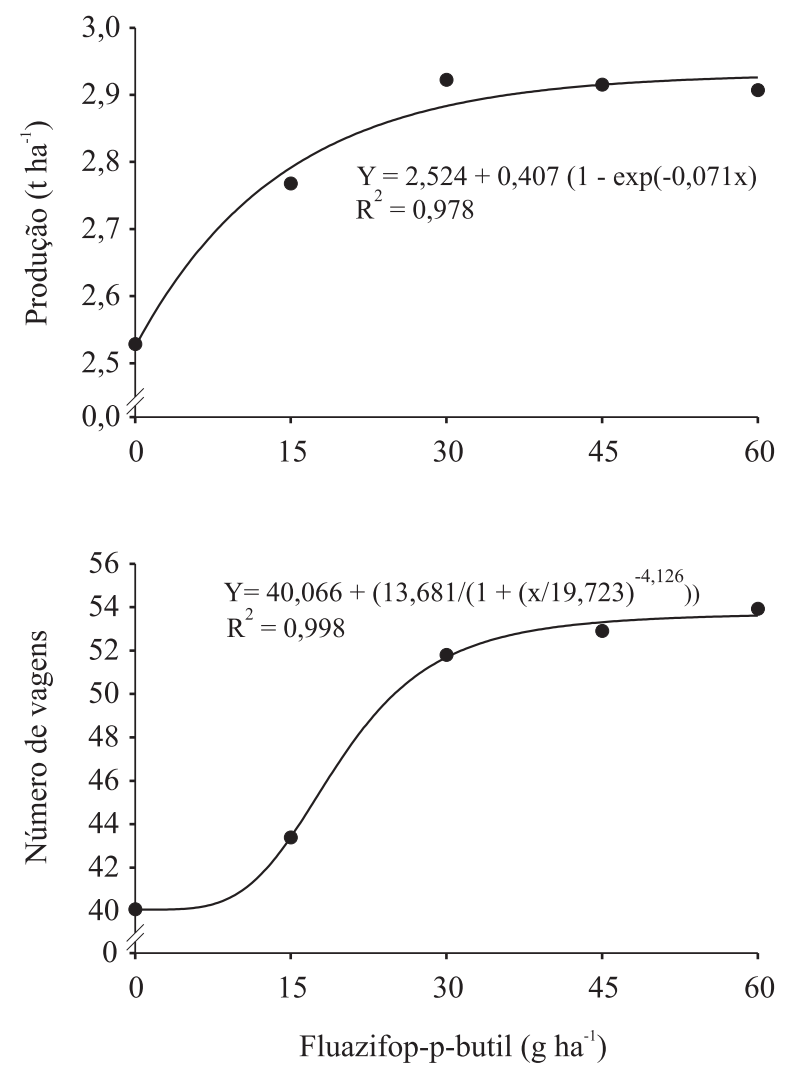

Figura 2. Produção e número de vagens por planta de soja consorciada com Brachiaria brizantha, em função de doses de graminicida. umidade (Figura 3), o que também foi constatado por outros autores (Andreoli \& Beltoft, 1979; Batista Filho \& Barros, 1980). Na dessecação realizada nos estádios R7 ou R8, o teor de umidade foi de 17,47 e $17,06 \%$, respectivamente, sendo de $18,24 \%$ nas plantas nãodessecadas. As diferentes doses do graminicida resultaram na presença ou ausência de B. brizantha na entrelinha da soja. A maior densidade de plantas em uma mesma área resulta em um ambiente mais úmido, em virtude da menor circulação de ar dentro do dossel. Por causa da ausência de efeito de doses do graminicida na variável teor de água dos grãos da soja, a presença da forrageira não interferiu nesta variável.

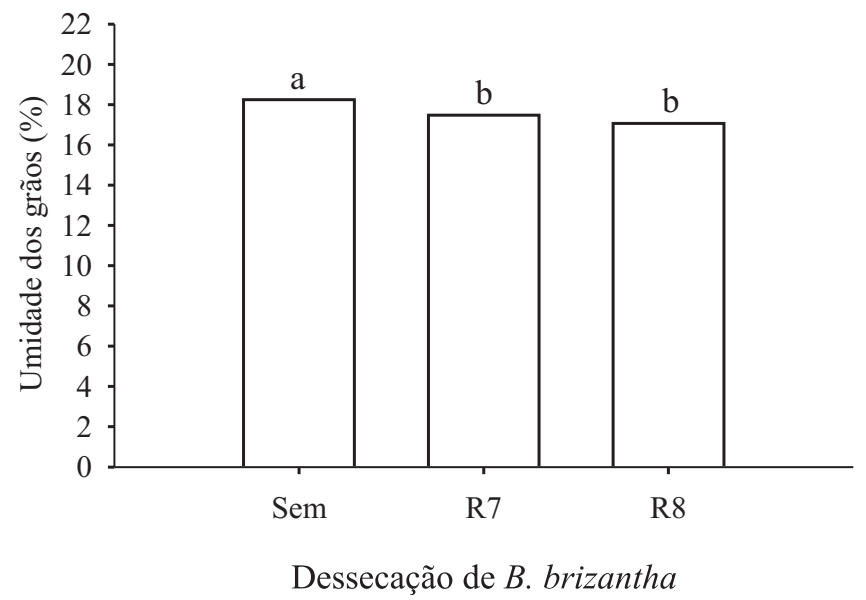

Figura 3. Umidade dos grãos de soja, na época da colheita, em razão dos manejos de dessecação de Brachiaria brizantha, nas fases de desenvolvimento R7 ou R8. Médias com letras iguais não diferem entre si pelo teste de Tukey a 5\% de probabilidade.

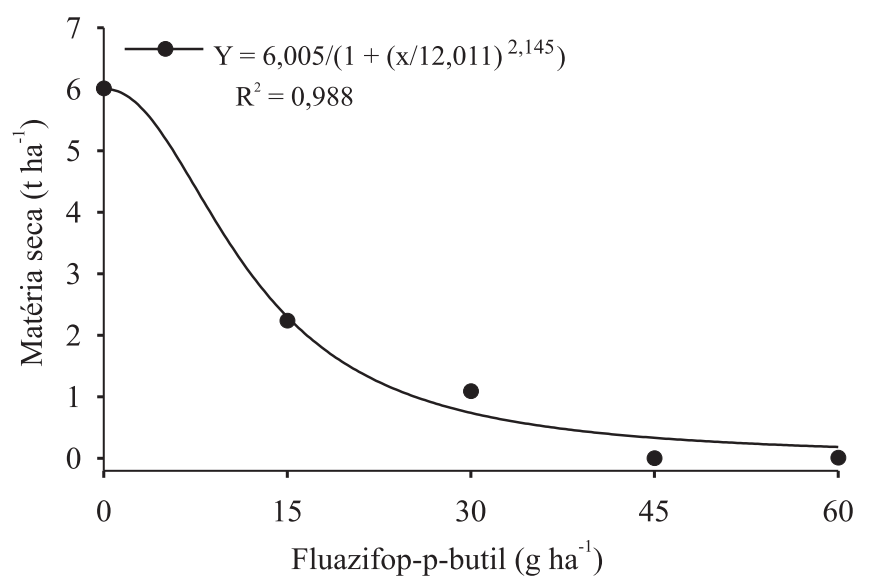

Figura 4. Massa de matéria seca de Brachiaria brizantha consorciada com soja, em função de doses de fluazifop-pbutil, avaliada na colheita da soja. 
Observou-se efeito do graminicida no acúmulo de matéria seca de $B$. brizantha por ocasião da colheita da soja. Houve queda acentuada da matéria em função das doses do graminicida (Figura 4). B. brizantha consorciada com a soja, sem aplicação do graminicida, acumulou $6 \mathrm{tha}^{-1}$ de matéria seca, considerada quantidade adequada ao plantio direto (Gomes, 1997). Considerando que B. brizantha em monocultivo acumulou $13 \mathrm{tha}^{-1}$, a interferência da soja sobre $B$. brizantha causou redução de $55 \%$ na matéria seca da forrageira, o que foi atribuído ao efetivo sombreamento exercido pela soja sobre $B$. brizantha. Nenhum tratamento em consórcio se igualou a $B$. brizantha em monocultivo.

Na Tabela 1, são apresentadas notas referentes ao grau de dificuldade de colheita mecânica da soja em presença de $B$. brizantha. Os manejos de dessecação foram comparados em cada dose do graminicida. Observa-se diferença entre os manejos apenas nas doses de 0 e $15 \mathrm{~g} \mathrm{ha}^{-1}$ do graminicida. Nas demais doses, o acúmulo de matéria seca da forrageira foi extremamente reduzido, o que viabilizou a colheita mecânica mesmo sem dessecação. Contudo, na dose zero, o tratamento sem dessecação tornou a colheita mecânica inviável (nota 4,5), porém, a dessecação feita nos estádios R7 ou R8 da soja viabilizou a colheita mecânica (nota 2,12).

Tabela 1. Notas referentes ao grau de dificuldade de colheita mecânica de soja consorciada com Brachiaria brizantha, com doses reduzidas de graminicida, dessecada ou não com paraquat (400 $\mathrm{g} \mathrm{ha}^{-1}$ ) nos estádios R7 ou R8 da soja, avaliada na colheita da soja ${ }^{(1)}$.

\begin{tabular}{lccccc}
\hline Manejo & \multicolumn{5}{c}{ Doses de graminicida $\left(\mathrm{g} \mathrm{ha}^{-1}\right)$} \\
\cline { 2 - 6 } & 0 & 15 & 30 & 45 & 60 \\
\hline Sem dessecação & $4,50 \mathrm{a}$ & $3,12 \mathrm{a}$ & $1,35 \mathrm{a}$ & $1,00 \mathrm{a}$ & $1,00 \mathrm{a}$ \\
Dessecada R7 & $2,12 \mathrm{~b}$ & $1,95 \mathrm{~b}$ & $1,05 \mathrm{a}$ & $1,05 \mathrm{a}$ & $1,00 \mathrm{a}$ \\
Dessecada R8 & $2,12 \mathrm{~b}$ & $1,95 \mathrm{~b}$ & $1,15 \mathrm{a}$ & $1,12 \mathrm{a}$ & $1,12 \mathrm{a}$ \\
\hline
\end{tabular}

${ }^{(1)}$ Grau de dificuldade de colheita mecânica (5 = inviável; 1 = perfeitamente viável); médias seguidas por letras iguais, na coluna, não diferem entre si pelo teste de Tukey a 5\% de probabilidade.

Tabela 2. Massa de matéria seca $\left(\mathrm{t} \mathrm{ha}^{-1}\right)$ de $B$. brizantha consorciada com soja, com doses reduzidas de graminicida, dessecada ou não com paraquat ( $400 \mathrm{~g} \mathrm{ha}^{-1}$ ) nos estádios R7 ou R8 da soja, avaliada aos 60 dias após a colheita desta ${ }^{(1)}$.

\begin{tabular}{lccccc}
\hline Manejo & \multicolumn{5}{c}{ Doses de graminicida $\left(\mathrm{g} \mathrm{ha}^{-1}\right)$} \\
\cline { 2 - 6 } & 0 & 15 & 30 & 45 & 60 \\
\hline Sem dessecação & $9,26 \mathrm{aA}$ & $7,49 \mathrm{aA}$ & $0,99 \mathrm{aB}$ & $0,12 \mathrm{aB}$ & $0,04 \mathrm{aB}$ \\
Dessecada R7 & $4,81 \mathrm{bA}$ & $4,60 \mathrm{bA}$ & $1,05 \mathrm{aB}$ & $0,00 \mathrm{aB}$ & $0,54 \mathrm{aB}$ \\
Dessecada R8 & $3,57 \mathrm{bA}$ & $1,67 \mathrm{cAB}$ & $0,25 \mathrm{aB}$ & $0,00 \mathrm{aB}$ & $0,00 \mathrm{aB}$ \\
\hline
\end{tabular}

${ }^{(1)}$ Médias seguidas por letras iguais, maiúsculas na linha e minúsculas na coluna, não diferem entre si pelo teste de Tukey a 5\% de probabilidade.
Quanto ao acúmulo de matéria seca de B. brizantha, 60 dias depois da colheita da soja, houve interação de doses e manejos. A partir de $30 \mathrm{~g} \mathrm{ha}^{-1}$ de graminicida, houve acúmulo reduzido de matéria seca (Tabela 2), o que confirma a alta suscetibilidade da forrageira ao graminicida. Comparando as doses dentro de cada manejo, verificou-se que não houve diferença no acúmulo de matéria seca de $B$. brizantha entre as doses de 30, 45 e $60 \mathrm{~g} \mathrm{ha}^{-1}$ do graminicida, que apresentaram acúmulo inferior ao proporcionado pelas doses de 0 e $15 \mathrm{~g} \mathrm{ha}^{-1}$ do graminicida, as quais não diferiram entre si dentro de nenhum manejo.

Na comparação dos manejos de $B$. brizantha dentro de cada dose, observou-se que, em virtude do efetivo controle da forrageira pelo graminicida a partir de $30 \mathrm{~g} \mathrm{ha}^{-1}$, não houve diferença entre os manejos de dessecação. Contudo, o manejo sem aplicação de dessecante, nas doses de 0 e $15 \mathrm{~g} \mathrm{ha}^{-1}$ de graminicida, proporcionou maior acúmulo de matéria seca de B. brizantha em relação aos tratamentos dessecados. Na dose zero, as aplicações do dessecante no estádio R7 ou R8 da soja não diferiram entre si, visto que, no tratamento sem aplicação do graminicida, houve maior acúmulo de matéria seca de $B$. brizantha, o que conferiu maior capacidade de rebrota das plantas, nivelando o intervalo entre as épocas de dessecação. Entretanto, com $15 \mathrm{~g} \mathrm{ha}^{-1}$ de graminicida, a dessecação em R7 proporcionou maior acúmulo de matéria seca que em R8, uma vez que a capacidade de rebrota da forrageira foi comprometida pelo graminicida. Segundo Postiglioni (1998), B. brizantha cv. Marandu apresenta baixa taxa de crescimento durante o outono, o que limitou ainda mais a capacidade de rebrota das plantas submetidas ao graminicida.

\section{Conclusões}

1. A cultivar Marandu de B. brizantha apresenta redução de 55\% de matéria seca em consórcio com a cultivar de soja UFV 16, e é altamente suscetível à ação do graminicida fluazifop-p-butil associado à interferência da soja.

2. A dessecação do consórcio entre soja e B. brizantha cv. Marandu com paraquat, nos estádios R7 ou R8 da soja, independentemente da aplicação de graminicida, favorece a colheita mecânica da soja, e é alternativa viável para formação de palha no plantio direto.

\section{Referências}

ALMEIDA, F.S.; PINEDA-AGUILAR, A.; RODRIGUES, B.N. Resíduos de paraquat em grão de soja quando usado como dessecante da cultura. Planta Daninha, v.9, p.85-91, 1991. 
AMARAL, M. Plantio direto evolui no Brasil. Informe Agropecuário, v.22, p.3, 2001.

ANDREOLI, C.; BELTOFT, D.C. Dessecantes no rendimento e na qualidade da semente de soja. Pesquisa Agropecuária Brasileira, v.14, p.135-139, 1979.

BATISTA FILHO, O.C.; BARROS, A.C.S.A. Efeitos de dessecantes na maturação e na qualidade de sementes de soja. Tecnologia de Sementes, v.3, p.19-26, 1980.

COBUCCI, T. Manejo integrado de plantas daninhas em sistema de plantio direto.In: ZAMBOLIM, L. (Ed.) Manejo integrado fitossanidade: cultivo protegido, pivô central e plantio direto. Viçosa: UFV, 2001. p.583-624.

DURIGAN, J.C.; CARVALHO, N.M. Aplicação em pré-colheita de dessecante em duas cultivares de soja (Glycine max (L.) Merrill) II. Efeitos sobre a incidência de fungos nas sementes. Planta Daninha, v.3, p.115-121, 1980.

FEHR, W.R.; CAVINESS, C.E.; BURMOOD, D.T.; PENNINGTON, J.S. Stage of development descriptions for soybeans, Glycine max (L.) Merrill. Crop Science, v.11, p.929931, 1971.

GOMES, A. da S. O que rende a cobertura morta. A Granja, v.53, p.47-49, 1997.

POSTIGLIONI, S.R. Potencial para produção de carne da Brachiaria brizantha, Setaria anceps cv. Kazungula e Cynodon nlemfuensis cv. Coastcross-1 na região dos Campos Gerais do Paraná, Brasil. Pasturas Tropicales, v.20, p.9-14, 1998.

RITCHIE, S.; HANWAY, J.J.; THOMPSON, H.E. How a soybean plant develops. Ames: Iowa State University of Science and Technology, 1982. 20p. (Special Report, 53).

RODRIGUES, B.N.; ALMEIDA, F.S. Guia de herbicidas. 4.ed. Londrina, 1998. 648p.

SATURNINO, H.M. Evolução do plantio direto e as perspectivas nos cerrados. Informe Agropecuário, v.22, p.5-12, 2001.

SILVA, A.C.; FERREIRA, L.R.; SILVA, A.A.; PAIVA, T.W.B.; SEDIYAMA, C.S. Efeitos de doses reduzidas de fluazifop-p-butil no consórcio entre soja e Brachiaria brizantha. Planta Daninha, v.22, p.429-435, 2004.

Recebido em 21 de fevereiro de 2005 e aprovado em 7 de junho de 2005 